\title{
Application of intuitionistic fuzzy numbers in SWOT analysis
}

\section{Emad Roghanian* and Baharak Ghorbani}

Department of Industrial Engineering, K.N. Toosi University of Technology,

Tehran, Iran

Email: E_roghanian@kntu.ac.ir

Email:Bh.ghorbani@mail.kntu.ac.ir

*Corresponding author

\section{Mohammad Alipour}

Sustainable Energies Group, AUT Office of Sustainability, Amirkabir University of Technology (Tehran Polytechnic),

Tehran, Iran

Email: Alipour.m.86@gmail.com

\begin{abstract}
Strategic studies are of high importance in every business administration. Some of them, like strengths, weaknesses, opportunities, threats (SWOT), can be used widely. However, uncertainty is always considered as a major obstacle for extracting strategies from these techniques. On the other hand, introduction of fuzzy logic facilitates the connection between real world managerial problems and deterministic mathematics. This paper thus focused on vague characteristic of the data used in SWOT analysis, and tried to solve it by utilisation of the intuitionistic fuzzy numbers (IFN), as a transformation which enables the outcome of this procedure to be identified more explicitly.
\end{abstract}

Keywords: strengths, weaknesses, opportunities, threats; SWOT; fuzzy set; intuitionistic fuzzy number; IFN; $\alpha$-cut.

Reference to this paper should be made as follows: Roghanian, E. and Ghorbani, B. and Alipour, M. (xxxx) 'Application of intuitionistic fuzzy numbers in SWOT analysis', Int. J. Industrial and Systems Engineering, Vol. X, No. Y, pp.000-000.

Biographical notes: Emad Roghanian obtained his BS degree in Industrial Engineering from Isfahan University of Technology (IUT), Isfahan, Iran, in 1995, and a MS and $\mathrm{PhD}$ degrees in Industrial Engineering from Iran University of Science and Technology (IUST), Tehran, Iran, in 1999 and 2007, respectively. $\mathrm{He}$ is currently an Associate Professor in the Department of Industrial Engineering at Khaje Nasir Toosi University of Technology (KNTU), Tehran, Iran. His research interests include: logistic and supply chain management, project management, and performance evaluation.

Baharak Ghorbani obtained her BS and MS degrees in Industrial Engineering from Khaje Nasir Toosi University of Technology (KNTU), Tehran, Iran, in 2012 and 2014, respectively. Her research interests include: project scheduling and management, mathematical modelling, and meta-heuristic algorithms. 
Mohammad Alipour is an associate researcher at Sustainable Energies Group, Office of Sustainability at Amirkabir University of Technology (Tehran Polytechnic), Tehran, Iran. His research interests include: fuzzy decision analysis, lean manufacturing, energy, and future studies.

\section{Introduction}

Competitive circumstances in recent years are considered as a big deal for every business all around the world. To firms, competitiveness means the ability to compete in world markets with a global strategy. As a result, companies have to create and maintain a competitive advantage, and be able to achieve better performance levels than their competitors (Pereira-Moliner et al., 2015). This is one of the main challenges confronting every firm. Thus, most companies engaged in strategic planning to become or stay competitive in the long run. Strategy has to capture an internal and external aspect, which means to comprise competencies and market opportunities (Pahl and Richter, 2007). That is mainly the importance of the strategic tools and analysis today. Several tools can be utilised to perform a strategic study, including both simple and complex methods. The aptness of the method used is clarified by the expert who does the research. However, some of them are used in approximately every strategic investigation, SWOT is one of those basic methods. Besides, complexity involved in the interpretation of the given information in strategic researches is considered as an obstacle to achieve clear results. This paper introduces a new approach which utilised intuitionistic fuzzy numbers (IFN) as a mean to overcome the ambiguity in SWOT. Furthermore, this method can be used to prioritise the extractable strategies with the help of $\alpha$-cut in fuzzy logic.

\section{Strengths, weaknesses, opportunities and treats}

Strengths, weaknesses, opportunities and treats (SWOT) analysis is a strategic planning tool used to evaluate the SWOT involved in a project or in a business venture, which dates back to ' 60 s. The SWOT analysis examines both helpful and harmful factors that originate from both internal and external of the organisation or a strategic plan. The internal assessment is conducted to illustrate strengths and weaknesses of an organisation or a strategic plan while the external assessment is applied to discover opportunities and threats (Chen et al., 2014). Strengths stand for any available resources that could be utilised to advance the performance. Weaknesses are deficiencies, which may reduce competitive advantages, efficiency, or financial resources. Opportunities are external changes that can contribute to an additional development, and threats are outside parameters that may cause problems (Paliwal, 2006). A schema of the tool is shown in Figure 1. The framework of SWOT was originally invented for business and marketing analysis and has been broadly adopted in other research fields including: energy management, health education, social work, tourism management, environmental strategies, agricultural business, social media and, etc. (Aiyelaagbe et al., 2015; Dzonzi-Undi and Li, 2015; Fernandez, 2009; Jaber et al., 2015; Sharma, 2005; Shi, 2016; Westhues et al., 2001). 
Figure 1 Scheme of SWOT analysis (see online version for colours)

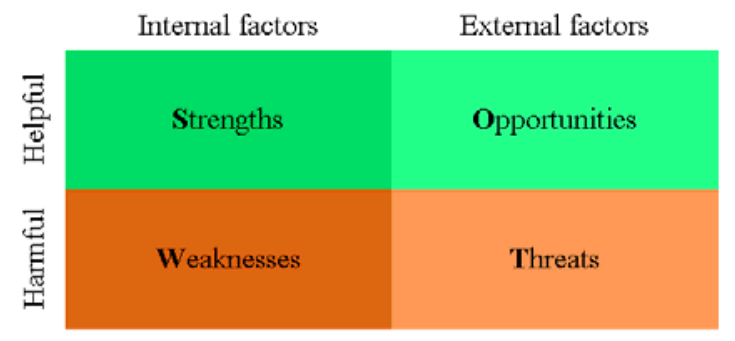

Weihrich (1982) introduces SWOT matrix as a tool for situation analysis. SWOT can also be used when strategy alternative emerges and the relevant decision context needs to be analysed (Igliński et al., 2015). The importance of SWOT analysis lies in its ability to help clarify and summarise the key issues facing a business. In other words, the SWOT analysis pursues an integrated approach including key company and environmental variables. The objective is the confrontation of the company's internal strengths and its weakness as well as company-external business opportunities and threats in order to generate possible strategic options (Böhm, 2008). The main purpose of SWOT is to help the managers to adopt a strategy in order to maximise strengths and minimise weaknesses as a mean to take advantages of external opportunities and overcome the threats. However, when these factors (SWOT) come together, other inferences can be figured out by considering them all simultaneously. A SWOT can be performed for companies, departments and divisions. Whatever the focus is, the results will be specific for each. It should be noted that a unique character might be interpreted in different terms according to the nature of study and the firm.

The main advantage of SWOT is its simplicity. Preparing a map of current situation of the organisation or the list of treats and opportunities tied together, which helps the firm to have a balanced understanding of the market, are other advantages of this method (Suh, 2014). SWOT has some disadvantages as well. A typical SWOT analysis is usually a simple list which is not presented critically. If an expert is focusing on just compiling lists he or she may have difficulties in defining how to achieve the effective strategies. Taking a list approach can also result in items not being prioritised. For example, a long list of weaknesses may appear to be 'cancelled out' by a longer list of strengths, regardless of how significant those weaknesses are. The best SWOT analysis will be more than a simple checklist. It will consider the degree of strength and weakness versus its competitors to determine how good that strength really is. Simultaneously, an efficient SWOT analysis should consider the importance of an opportunity or threat and implies how these inter-related factors interact with strengths and weaknesses.

\section{Fuzzy logic}

Zadeh (1965) introduced a new branch of mathematics known as fuzzy logic. It is a system of reasoning and computation in which the objects of reasoning and computation are classes with unsharp (fuzzy) boundaries. In fuzzy logic everything is, or is allowed to be, a matter of degree, including degrees. That is, in fuzzy logic, objects of discourse and analysis are, or are allowed to be, associated with imperfect information. Imperfect 
information is information which in one or more respects is imprecise, incomplete, uncertain, fragment, incomplete, not fully reliable, vague or partially true (Khanesar et al., 2012; Zadeh, 2009). Today, the term fuzzy logic is used predominantly in its wide sense. In particular, what is used in almost all applications of fuzzy logic is fuzzy logic in its wide sense (Zadeh, 2015).

This system of reasoning can be considered as the significant step toward uniting the real world and mathematics. Briefly, it was based on the fact that, human statements can be categorised in other terms rather than just True and False. However, in classical mathematics, we are familiar with what we call crisp values. Actually, Zadeh defined a membership value for each statement within True and False, more scientifically a value selected from $[0,1]$ interval. When the statement is true, the membership value is said to be one while a false statement receives zero. Specifying these two milestones, other statements, used in real human language and conception, can be defined in mathematic world by receiving a value between zero and one.

Introducing fundamentals of fuzzy logic and understanding the worth of such a logic, researchers and scientists all over the world commence their attempt to form different aspects of this young logic. Simultaneously, another group focused on the application in industry, science and, etc. (Gottwald, 1993; Hagras et al., 2015; Krishnamoorthy et al., 2012; Roghanian and Alipour, 2014; Taheri et al., 2012; Verbruggen et al., 2013).

\subsection{Fuzzy number}

Generally, a fuzzy number (let say $\tilde{A}$ ) is defined as any subset of the real numbers $(R)$, with membership function, denoted by $\mu_{A}$ or $f$, satisfies the conditions below (Dubois and Prade, 1980):

$1 \mu_{A}$ is a continuous function from real numbers to the interval $[0,1]$

$2 \mu_{A}(x)=0$ for $-\infty \leq x \leq c$

$3 \mu_{A}(x)=f^{L}$ is strictly increasing on $[c, a]$

$4 \quad \mu_{A}(x)=w$ for $a \leq x \leq b$

$5 \quad \mu_{A}(x)=f^{R}$ is strictly decreasing on $[b, d]$

$6 \mu_{A}(x)=0$ for $d \leq \mathrm{x} \leq+\infty$.

Figure 2 A typical illustration of a fuzzy number

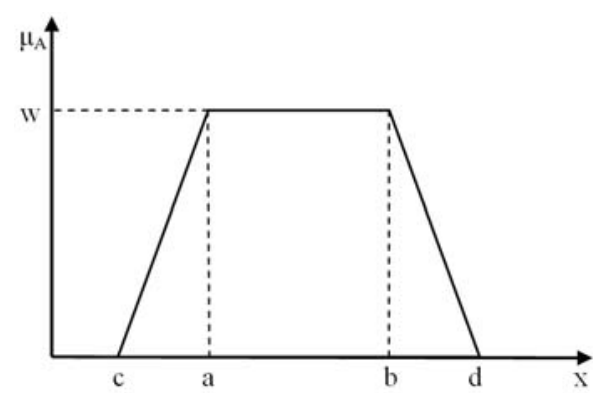


Definition 1: If $a \neq b$ then this number is called a trapezoidal fuzzy number, illustrated in Figure 2, and if $a=b$ then $\tilde{A}$ is a triangular fuzzy number.

Definition 2: The height of a fuzzy number is the largest amount of membership function. It is shown by ' $w$ ' in Figure 2.

Definition 3: If the height of a fuzzy number is equal to one, then the number is called a normal fuzzy number (Chen, 1999).

\subsection{Intuitionistic fuzzy numbers}

Although the introduction of the fuzzy logic was an important step toward the formulation of a new generation of problems to be solved in a systematic approach, there are still problems which cannot be defined properly even with the help of fuzzy logic. Another instance of this deficiency is about the formulation of problems which requires deterministic data entry due to their high importance. Once more, the fuzzy logic prepares an appropriate tool to solve and model these problems. IFN (Atanassov, 1986), denoted by IFN, is the proper definition which helps the formulation of linguistic variables which contain uncertainty in their nature.

The conception of intuitionistic fuzzy set (IFS) can be viewed as an appropriate approach in the case where available information is not sufficient to define the impreciseness by the conventional fuzzy set. IFS add an extra degree to the usual fuzzy sets in order to model hesitation and uncertainty about the membership degree of belonging. In fuzzy sets, the degree of acceptance is considered only but IFS is characterised by a membership function and a non-membership function so that the sum of both values is less than one (Kahraman and Yanik, 2015). It is more abundant and flexible for the IFNs to express and describe information than the fuzzy numbers when uncertain information is involved. Recently, there are a number of studies involving IFNs and its application (Chen et al., 2016; Dubey and Mehra, 2011; Guha and Chakraborty, 2010; Liu, 2013; Mahapatra and Roy, 2009; Wei et al., 2014; Zhao et al., 2015). And with its reliability to deal with vagueness, a plethora of studies have been conducted to further develop and enrich IFS theory (Chang et al., 2006; Garg et al., 2012; Garg and Rani, 2013; Lei and Xu, 2015; Wan and Dong, 2015; Wu and Chiclana, 2014).

There are lots of variables which are defined by the experts and as they are human or because of the nature of the variable, the value of the variable cannot be defined exactly. Suppose that a teacher is asked to decide about the intelligence of two of his/her students. His/her answer might be "I think that Student 1 is more intelligent than student 2, but I'm not sure". How can we transform this answer into a variable? The use of IFS enables us to define such answers to modelling procedure.

Definition 4: An IFS $A$ define on a universe $X$ is given by Atanassov (1986):

$$
A=\left\{x, \mu_{A}(x), v_{A}(x) \mid x \in X\right\},
$$

where

$$
\mu_{A}: X \rightarrow[0,1] \text { and } v_{A}: X \rightarrow[0,1],
$$

With the condition 


$$
0 \leq \mu_{A}(x)+v_{A}(x) \leq 1,
$$

for all $x \in X$.

Figure 3 A representation of an IFN (see online version for colours)

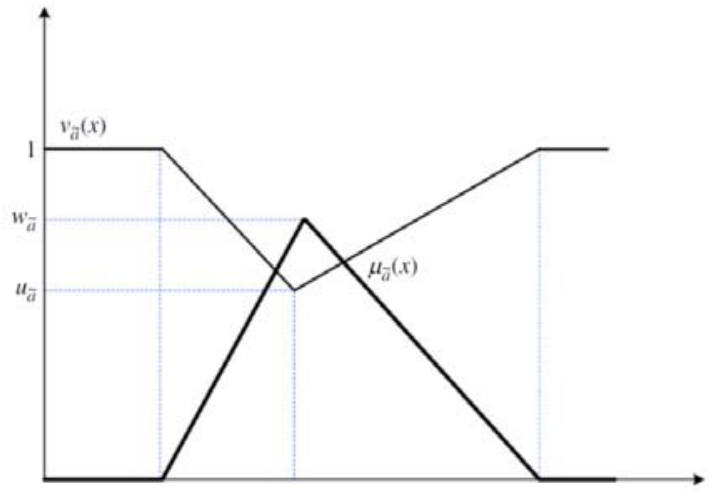

The numbers $\mu_{A}(x)$ and $v_{A}(x)$ denote the degree of membership and the degree of non-membership of $x$ to $A$, as shown in Figure 3 (Li, 2010). For an IFS $A$ in $X$ we call the intuitionistic index of an element $x \in X$ in $A$ the following expression:

$$
\pi_{A}(x)=1-\mu_{A}(x)-v_{A}(x) .
$$

We can consider $\pi_{A}(x)$ as a hesitancy degree of $x$ to $A$ (Atanassov, 1986). From above equation, it is evident that

$$
0 \leq \pi_{A}(x) \leq 1,
$$

for all $x \in X$.

Remark 1: An ordinary fuzzy number can also be represented as an IFN like this:

$$
A=\left\{x, \mu_{A}(x), 1-\mu_{A}(x) \mid x \in X\right\} .
$$

With $\pi_{A}(x)=0$ for all $x \in X$.

The complementary set $A^{c}$ of $A$ is defined as:

$$
A^{c}=\left\{\left(x, v_{A}(x), \mu_{A}(x)\right) \mid x \in X\right\} .
$$

Suppose that $A$ and $B$ are two arbitrary IFNs from set $X$, the following are held (Wu and Zhang, 2011):

$$
\begin{aligned}
& A \wedge B=\left\{\left(x, \mu_{A}(x) \wedge \mu_{B}(x), v_{A}(x) \wedge v_{B}(x)\right) \mid x \in X\right\}, \\
& A \vee B=\left\{\left(x, \mu_{A}(x) \vee \mu_{B}(x), v_{A}(x) \vee v_{B}(x)\right) \mid x \in X\right\}, \\
& A \oplus B=\left\{\left(x, \mu_{A}(x)+\mu_{B}(x)-\mu_{A}(x) \mu_{B}(x), v_{A}(x) v_{B}(x)\right) \mid x \in X\right\},
\end{aligned}
$$




$$
\begin{aligned}
& A \otimes B=\left\{\left(x, \mu_{A}(x) \mu_{B}(x), v_{A}(x)+v_{B}(x)-v_{A}(x) v_{B}(x)\right) \mid x \in X\right\}, \\
& \alpha A=\left\{\left(x, 1-\left(1-\mu_{A}(x)\right)^{\alpha},\left(v_{A}(x)\right)^{\alpha}\right) \mid x \in X\right\}, \text { for } \alpha \geq 0, \\
& A^{\alpha}=\left\{\left(x,\left(\mu_{A}(x)\right)^{\alpha}, 1-\left(1-v_{A}(x)\right)^{\alpha}\right) \mid x \in X\right\}, \text { for } \alpha \geq 0,
\end{aligned}
$$

\section{Application of intuitionistic numbers in SWOT}

As stated before SWOT is one of those strategic tools which is defined and structured with the SWOT from the point of view of experts from the firm or business. Obviously, experts use linguistic terms and statements. In most cases these statements are not deterministic; on the other hand, strategic studies are from high priority that emphasise that the results should be determined clearly. In this paper, we propose the use of the IFN in developing the SWOT analysis. The following steps are defined to prepare a more reliable SWOT. Furthermore a demonstrative example of this procedure is given.

Step 1 First of all, the process commences with the definition of the internal and external factors. In this step the experts and the analyst must list the important and effective factors due to the scope of research (let ' $n$ ' be the number of factors in the list). The result of this step must be categorised in two main groups named internal and external factors.

Step 2 The second task to be done is the division of the listed factors into specific subsets. Actually, the internal factors must be separated into Strengths and weaknesses, while the external factors are divided into Opportunities and Treats.

Step 3 The third step enables us to achieve the accuracy needed. The expert is asked to define the priority of each factor among other factors in its group. Note that this step is the main part of data preparation. Each factor's priority is defined in its own group by the use of an IFS. The following expressions should be defined for each factor with respect to its group. The variable $P_{i}$ is defined for this purpose.

$P_{i}=(x, \mu, v) ; x \rightarrow[0,1] ; i=\{1,2,3, \ldots, n\}$

The value for each factor is derived by the comparison of factors in each group defines in second step. It seems more rational that the analyst gathers a team of expert from different aspects of view. A combination of an optimistic expert, a pessimistic and a realistic one can be the ideal group of experts. In this case, $P_{i}$

(optimistic), $P_{i}^{\prime}$ (pessimistic) and $P_{i}^{\prime \prime}$ (most probable or realistic).

Step 4 State a unique IFN for the priority of each factor using the following average method:

$\rho_{i}=\frac{P_{i} \oplus 2 P_{i}^{\prime} \oplus P_{i}^{\prime \prime}}{4} \quad$ or $\quad \rho_{i}=\frac{P_{i} \oplus P_{i}^{\prime \prime}}{2}$ 
Step 5 Now, we are able to define the SWOT matrix. Note that the value of each intersection (let say the intersection of the $i^{\text {th }}$ row and $j^{\text {th }}$ column) is defined as follows:

$$
M_{i j}=\rho_{i} \otimes \rho_{j}
$$

Step 6 Now, the analyst can offer the manager, due to the significance level set to $\mathrm{him} / \mathrm{her}$. All he/she has to do is to make an $\alpha$-cut to obtain the required points and consequently the prioritised factors for concluding the appropriate strategy.

\section{Illustrative example}

The example illustrated in this section is not a real case, because it is mentioned to facilitate the aptness of the proposed steps. Consequently, we avoid the extra explanations. This way the complexity of the procedures reduced effectively due to the target of this illustration.

Suppose that an analyst wants to perform a SWOT analysis. The manager of the firm being studied has assigned two of his experts in order to help the analyst. Assume that one of them was an optimistic person and the other one was pessimistic. As the team comes together the following statements were derived out from their point of view (the results of the first two steps mentioned in Section 4); Internal and external factors (totally 16 factors) facing the firm assume to be as follow:

There are five main strength factors (factors number 1 to 5), four Weakness point (6 to 9), four Opportunities (10 to 13); and at last three factors are determined to be Treats $(14,15$ and 16).

In the third step, experts were asked to assign the priority of each factor among other factors in its group. The team transformed the statements into IFN. Table 1 shows the outcome of this step.

Table 1 Priority of each factor indicated by experts

\begin{tabular}{cccccccc}
\hline & \multicolumn{3}{c}{ Pessimistic expert } & & \multicolumn{3}{c}{ Optimistic expert } \\
\cline { 2 - 3 } \cline { 6 - 7 } \cline { 6 - 7 } & $\mu$ & $v$ & $\pi$ & & $\mu$ & $v$ & $\pi$ \\
\hline 1 & 0.70 & 0.20 & 0.10 & & 0.80 & 0.10 & 0.10 \\
2 & 0.40 & 0.50 & 0.10 & & 0.60 & 0.20 & 0.20 \\
3 & 0.80 & 0.10 & 0.10 & & 0.80 & 0.10 & 0.10 \\
4 & 0.80 & 0.20 & 0.00 & & 0.90 & 0.10 & 0.00 \\
5 & 0.70 & 0.10 & 0.20 & & 0.80 & 0.10 & 0.10 \\
6 & 0.70 & 0.10 & 0.20 & & 0.80 & 0.10 & 0.10 \\
7 & 0.60 & 0.30 & 0.10 & & 0.70 & 0.20 & 0.10 \\
8 & 0.70 & 0.10 & 0.20 & & 0.80 & 0.10 & 0.10 \\
9 & 0.90 & 0.10 & 0.00 & & 0.90 & 0.00 & 0.10 \\
10 & 0.60 & 0.30 & 0.10 & & 0.80 & 0.10 & 0.10 \\
\hline
\end{tabular}


Application of intuitionistic fuzzy numbers in SWOT analysis

Table 1 Priority of each factor indicated by experts (continued)

\begin{tabular}{cccccccc}
\hline & \multicolumn{3}{c}{ Pessimistic expert } & & \multicolumn{3}{c}{ Optimistic expert } \\
\cline { 2 - 3 } \cline { 6 - 8 } \cline { 5 - 7 } & $\mu$ & $v$ & $\pi$ & & $\mu$ & $v$ & $\pi$ \\
\hline 11 & 0.60 & 0.20 & 0.20 & & 0.80 & 0.20 & 0.00 \\
12 & 0.80 & 0.10 & 0.10 & & 1.00 & 0.00 & 0.00 \\
13 & 0.80 & 0.20 & 0.00 & & 0.90 & 0.10 & 0.00 \\
14 & 0.80 & 0.10 & 0.10 & & 0.60 & 0.20 & 0.20 \\
15 & 0.70 & 0.20 & 0.10 & & 0.80 & 0.10 & 0.10 \\
16 & 0.60 & 0.20 & 0.20 & & 0.70 & 0.20 & 0.10 \\
\hline
\end{tabular}

Table 2 is a presentation of the average of the IFNs which stated by Table 1, using the second part of equation (12).

Table 2 Average of the IFNs

\begin{tabular}{lccc}
\hline$i$ & \multicolumn{3}{c}{ Average of IFNs for each factor } \\
\cline { 2 - 4 } & $\mu$ & $v$ & $\pi$ \\
\hline 1 & 0.94 & 0.02 & 0.04 \\
2 & 0.76 & 0.10 & 0.14 \\
3 & 0.96 & 0.01 & 0.03 \\
4 & 0.98 & 0.02 & 0.00 \\
5 & 0.94 & 0.01 & 0.05 \\
6 & 0.94 & 0.01 & 0.05 \\
7 & 0.88 & 0.06 & 0.06 \\
8 & 0.94 & 0.01 & 0.05 \\
9 & 0.99 & 0.00 & 0.01 \\
10 & 0.92 & 0.03 & 0.05 \\
11 & 0.92 & 0.04 & 0.04 \\
12 & 1.00 & 0.00 & 0.00 \\
13 & 0.98 & 0.02 & 0.00 \\
14 & 0.92 & 0.02 & 0.06 \\
15 & 0.94 & 0.02 & 0.04 \\
16 & 0.88 & 0.04 & 0.08 \\
\hline
\end{tabular}

Continuing the steps, the SWOT matrix can be attained by step 5, as depicted in Tables 3 and 4.

Achieving the SWOT matrix the analyst is able to clarify the data needed by making an $\alpha$-cut (the manager defines the amount of $\alpha$ ). It is obvious that larger values of $\alpha$ lead to more accurate inferences, however the interpretation of the outcome of the final step is highly dependent on the nature of study. 
10 E. Roghanian et al.

Table 3 SWOT matrix-part 1

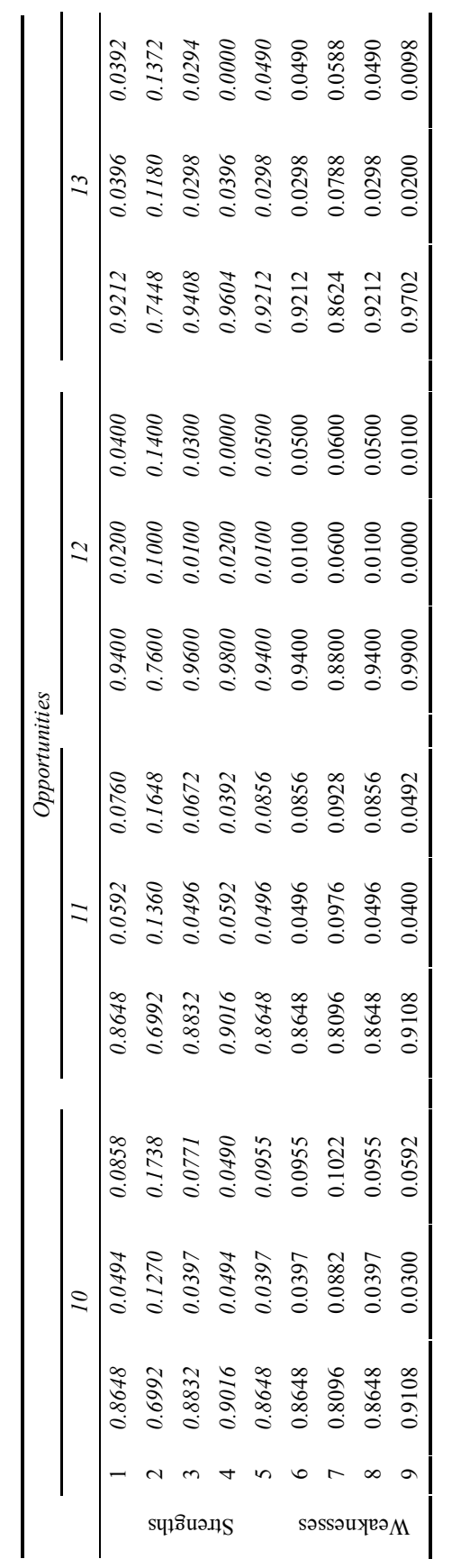


Application of intuitionistic fuzzy numbers in SWOT analysis

Table 4 SWOT matrix-part 2

\begin{tabular}{|c|c|c|c|c|c|c|c|c|c|c|}
\hline & \multicolumn{10}{|c|}{ Treats } \\
\hline & \multicolumn{4}{|c|}{14} & \multicolumn{3}{|c|}{15} & \multicolumn{3}{|c|}{16} \\
\hline \multirow{4}{*}{ 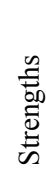 } & 1 & 0.8648 & 0.0396 & 0.0956 & 0.8836 & 0.0396 & 0.0768 & 0.8272 & 0.0592 & 0.1136 \\
\hline & 2 & 0.6992 & 0.118 & 0.1828 & 0.7144 & 0.118 & 0.1676 & 0.6688 & 0.136 & 0.1952 \\
\hline & 3 & 0.8832 & 0.0298 & 0.087 & 0.9024 & 0.0298 & 0.0678 & 0.8448 & 0.0496 & 0.1056 \\
\hline & 4 & 0.9016 & 0.0396 & 0.0588 & 0.9212 & 0.0396 & 0.0392 & 0.8624 & 0.0592 & 0.0784 \\
\hline \multirow{5}{*}{ 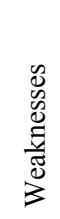 } & 5 & 0.8648 & 0.0298 & 0.1054 & 0.8836 & 0.0298 & 0.0866 & 0.8272 & 0.0496 & 0.1232 \\
\hline & 6 & 0.8648 & 0.0298 & 0.1054 & 0.8836 & 0.0298 & 0.0866 & 0.8272 & 0.0496 & 0.1232 \\
\hline & 7 & 0.8096 & 0.0788 & 0.1116 & 0.8272 & 0.0788 & 0.094 & 0.7744 & 0.0976 & 0.128 \\
\hline & 8 & 0.8648 & 0.0298 & 0.1054 & 0.8836 & 0.0298 & 0.0866 & 0.8272 & 0.0496 & 0.1232 \\
\hline & 9 & 0.9108 & 0.02 & 0.0692 & 0.9306 & 0.02 & 0.0494 & 0.8712 & 0.04 & 0.0888 \\
\hline
\end{tabular}

\section{Conclusions}

Despite of the fact that SWOT is one of the most popular strategic tools, it still has some fundamental deficiencies, including lack of considering vague and two sided factors, lack of prioritisation of the factors and strategies and too many extractable strategies that should be considered after the SWOT analysis. Today, with the help of new concept of logical sciences such as fuzzy logic some of these deficiencies which are actually results of the usage of binary-based Aristotle logic can be solved. Moreover, the application of fuzzy concept in interpretation of matrices has been recommended by Lin and Hsieh (2003). This article introduced a new approach which is based on the combination of IFN and SWOT. The proposed steps help to model the vagueness of factors in a systematic approach. Besides, the outcome of the SWOT procedure can be prioritised by the use of $\alpha$-cuts.

Although this paper has attempt to extract better results from SWOT analysis which are more confident and realistic, there are still efforts to decrease the number of extractable strategies, which is one of the main challenges of SWOT as a strategic, informative tool.

\section{References}

Aiyelaagbe, I.O., Harris, P.C. and Olowe, V.I.O. (2015) 'Skills gaps in organic agriculture and SWOT analysis in higher educational institutions (HEIs) in Anglophone West Africa', Organic Agriculture, pp.1-10.

Atanassov, K.T. (1986) 'Intuitionistic fuzzy sets', Fuzzy Sets and Systems, Vol. 20, No. 1, pp.87-96.

Böhm, A. (2008) The SWOT Analysis, Scholarly Paper, Seminar, University of Applied Sciences Berlin.

Chang, J.R., Chang, K.H., Liao, S.H. and Cheng, C.H. (2006) 'The reliability of general vague fault-tree analysis on weapon systems fault diagnosis', Soft Computing, Vol. 10, No. 7, pp.531-542. 
Chen, S.H. (1999) 'Ranking generalized fuzzy numbers with graded mean integration', Proceedings of the 8th International Fuzzy Systems Association World Congress, Vol. 2, pp.899-902.

Chen, S.M., Cheng, S.H. and Chiou, C.H. (2016) 'Fuzzy multiattribute group decision making based on intuitionistic fuzzy sets and evidential reasoning methodology', Information Fusion, Vol. 27, pp. 215-227.

Chen, W.M., Kim, H. and Yamaguchi, H. (2014) 'Renewable energy in eastern Asia: renewable energy policy review and comparative SWOT analysis for promoting renewable energy in Japan, South Korea, and Taiwan', Energy Policy, Vol. 74, pp.319-329.

Dubey, D. and Mehra, A. (2011) 'Linear programming with triangular intuitionistic fuzzy number', Proceedings of the 7th Conference of the European Society for Fuzzy Logic and Technology, pp.563-569, Atlantis Press.

Dubois, D. and Prade, H. (1980) Fuzzy Sets and Systems: Theory and Applications, Academic Press, New York.

Dzonzi-Undi, J. and Li, S. (2015) 'SWOT analysis of safety and environmental regulation for China and USA: its effect and influence on sustainable development of the coal industry', Environmental Earth Sciences, Vol. 74, No. 8, pp.6395-6406.

Fernandez, J. (2009) 'A SWOT analysis for social media in libraries', Online, Vol. 33, No. 5, pp.35-37.

Garg, H. and Rani, M. (2013) 'An approach for reliability analysis of industrial systems using PSO and IFS technique', ISA Transactions, Vol. 52, No. 6, pp.701-710.

Garg, H., Rani, M. and Sharma, S.P. (2012) 'Fuzzy RAM analysis of the screening unit in a paper industry by utilizing uncertain data', International Journal of Quality, Statistics, and Reliability, 14pp.

Gottwald, S. (1993) Fuzzy Sets and Fuzzy Logic: The Foundations of Application - from a Mathematical Point of View, Friedr. Vieweg \& Sohn Verlagsgesellschaft mbH, Wiesbaden, Germany.

Guha, D. and Chakraborty, D. (2010) 'A theoretical development of distance measure for intuitionistic fuzzy numbers', International Journal of Mathematics and Mathematical Sciences, 25pp.

Hagras, H., Alghazzawi, D. and Aldabbagh, G. (2015) 'Employing type-2 fuzzy logic systems in the efforts to realize ambient intelligent environments [application notes]', Computational Intelligence Magazine, Vol. 10, No. 1, pp.44-51, IEEE.

Igliński, B., Piechota, G., Iglińska, A., Cichosz, M. and Buczkowski, R. (2015) 'The study on the SWOT analysis of renewable energy sector on the example of the Pomorskie Voivodeship (Poland)', Clean Technologies and Environmental Policy, Vol. 18, No. 1, pp.45-61.

Jaber, J.O., Elkarmi, F., Alasis, E. and Kostas, A. (2015) 'Employment of renewable energy in Jordan: current status, SWOT and problem analysis', Renewable and Sustainable Energy Reviews, Vol. 49, pp.490-499.

Kahraman, C. and Yanik, S. (2015) Intelligent Decision Making in Quality Management: Theory and Applications, Vol. 97, Springer, London.

Khanesar, M.A., Kayacan, E., Teshnehlab, M. and Kaynak, O. (2012) 'Extended Kalman filter based learning algorithm for type-2 fuzzy logic systems and its experimental evaluation', IEEE Transactions on Industrial Electronics, Vol. 59, No. 11, pp.4443-4455.

Krishnamoorthy, A., Boopathy, S.R., Palanikumar, K. and Davim, J.P. (2012) 'Application of grey fuzzy logic for the optimization of drilling parameters for CFRP composites with multiple performance characteristics', Measurement, Vol. 45, No. 5, pp.1286-1296.

Lei, Q. and Xu, Z. (2015) 'Derivative and differential operations of intuitionistic fuzzy numbers', International Journal of Intelligent Systems, Vol. 30, No. 4, pp.468-498.

Li, D.F. (2010) 'A ratio ranking method of triangular intuitionistic fuzzy numbers and its application to MADM problems', Computers and Mathematics with Applications, Vol. 60, No. 6, pp.1557-1570. 
Lin, C. and Hsieh, P.J. (2003) 'A fuzzy decision support system for strategic portfolio management', Decision Support Systems, Vol. 38, No. 3, pp.383-398.

Liu, P. (2013) 'Some generalized dependent aggregation operators with intuitionistic linguistic numbers and their application to group decision making', Journal of Computer and System Sciences, Vol. 79, No. 1, pp.131-143.

Mahapatra, G.S. and Roy, T.K. (2009) 'Reliability evaluation using triangular intuitionistic fuzzy numbers arithmetic operations', International Journal of Computer, Electrical, Automation, Control and Information Engineering, Vol. 3, No. 2, pp.350-357.

Pahl, N. and Richter, A. (2007) SWOT Analysis-idea, Methodology and a Practical Approach, Scholarly Research Paper, University of Applied Sciences Berlin.

Paliwal, R. (2006) 'EIA practice in India and its evaluation using SWOT analysis', Environ. Impact Assess. Rev., Vol. 26, No. 5, pp.492-510.

Pereira-Moliner, J., Font, X., Tarí, J.J., Molina-Azorin, J.F., Lopez-Gamero, M.D. and Pertusa-Ortega, E.M. (2015) 'The Holy Grail: environmental management, competitive advantage and business performance in the Spanish hotel industry', International Journal of Contemporary Hospitality Management, Vol. 27, No. 5, pp.714-738.

Roghanian, E. and Alipour, M. (2014) 'A fuzzy model for achieving lean attributes for competitive advantages development using AHP-QFD-PROMETHEE', Journal of Industrial Engineering International, Vol. 10, No. 3, pp.1-11.

Sharma, M. (2005) 'Health Education in India: a strengths, weaknesses, opportunities, and threats (SWOT) analysis', International Electronic Journal of Health Education, Vol. 8, pp.80-85.

Shi, X. (2016) 'The future of ASEAN energy mix: a SWOT analysis', Renewable and Sustainable Energy Reviews, Vol. 53, pp.672-680.

Suh, J. (2014) 'Theory and reality of integrated rice-duck farming in Asian developing countries: a systematic review and SWOT analysis', Agricultural Systems, Vol. 125, pp.74-81.

Taheri, H., Neamatollahi, P., Younis, O.M., Naghibzadeh, S. and Yaghmaee, M.H. (2012) 'An energy-aware distributed clustering protocol in wireless sensor networks using fuzzy logic', Ad Hoc Networks, Vol. 10, No. 7, pp.1469-1481.

Verbruggen, H.B., Zimmermann, H.J. and Babuška, R. (2013) Fuzzy Algorithms for Control, Vol. 14, Kluwer Academic Publishers, Boston.

Wan, S.P. and Dong, J.Y. (2015) 'Power geometric operators of trapezoidal intuitionistic fuzzy numbers and application to multi-attribute group decision making', Applied Soft Computing, Vol. 29, pp.153-168.

Wei, G., Lin, R., Zhao, X. and Wang, H. (2014) 'An approach to multiple attribute decision making based on the induced Choquet integral with fuzzy number intuitionistic fuzzy information', Journal of Business Economics and Management, Vol. 15, No. 2, pp.277-298.

Weihrich, H. (1982) 'The TOWS matrix - a tool for situational analysis', Long Range Plan, Vol. 15, No. 2, pp.54-66.

Westhues, A., Lafrance, J. and Schmidt, G. (2001) 'A SWOT analysis of social work education in Canada', Social Work Education, Vol. 20, No. 1, pp.35-56.

Wu, J. and Chiclana, F. (2014) 'A risk attitudinal ranking method for interval-valued intuitionistic fuzzy numbers based on novel attitudinal expected score and accuracy functions', Applied Soft Computing, Vol. 22, pp.272-286.

$\mathrm{Wu}$, J.Z. and Zhang, Q. (2011) 'Multicriteria decision making method based on intuitionistic fuzzy weighted entropy', Expert Systems with Applications, Vol. 38, No. 1, pp.916-922.

Zadeh, L.A. (1965) 'Fuzzy sets', Information and Control, Vol. 8, No. 1, pp.338-353.

Zadeh, L.A. (2009) 'Toward extended fuzzy logic - a first step', Fuzzy Sets and Systems, Vol. 160, No. 21, pp.3175-3181.

Zadeh, L.A. (2015) 'Fuzzy logic - a personal perspective', Fuzzy Sets and Systems, Vol. 281, pp.4-20. 
Zhao, Q., Chen, H., Zhou, L., Tao, Z. and Liu, X. (2015) 'The properties of fuzzy number intuitionistic fuzzy prioritized operators and their applications to multi-criteria group decision making', Journal of Intelligent \& Fuzzy Systems: Applications in Engineering and Technology, Vol. 28, No. 4, pp.1835-1848. 